\title{
Isolation and Identification of Ammonia Nitrogen Degradation Strains from Industrial Wastewater
}

\author{
Cai-Hong Yu, Ya Wang, Tao Guo, Wan-Xin Shen, Ming-Xin Gu \\ College of Chemical \& Environmental Engineering, China University of Mining and Technology, Beijing, China \\ Email: caihongy@yahoo.com.cn
}

Received August 14, 2012; revised September 16, 2012; accepted September 26, 2012

\begin{abstract}
Nine strains of ammonia nitrogen degradation strains from $C_{1}$ to $C_{9}$ were isolated from industrial wastewater to study their degradation and conversion of ammonia nitrogen. The results showed that $\mathrm{C}_{2}$ strain with a high degradation activiity of ammonia nitrogen, and the ammonia nitrogen degradation rate of the activated $\mathrm{C}_{2}$ strain was $93 \%$ within $24 \mathrm{~h}$ when the initial concentration of ammonia nitrogen was $200 \mathrm{mg} / \mathrm{L}$ under the conditions of inoculation $10 \%$, temperature $35^{\circ} \mathrm{C}, \mathrm{pH} 7.0$, rotation $200 \mathrm{r} / \mathrm{min}$. And $\mathrm{C}_{2}$ was identified as Bacillus amyloliquefaciens.
\end{abstract}

Keywords: Industrial Wastewater; Ammonia Nitrogen; Degradation Strain; Degradation Characteristics

\section{Introduction}

With the rapid development and growth of Chinese economy, fertilizer, petrochemical and other industries, wastewater from chemical products production process which includes many pollutants such as phenolic compound, quinoline, ammonia nitrogen will cause certain damage to the environment and it will do more harm to human health. As we know, ammonia nitrogen discharged into water bodies will result in water quality decline or water eutrophication and will pollute the environment health, thus poses a threat to the ecological balance [1]. Biological nitrogen removal method is acknowledged to be a more economical, efficient method. When applied in treat wastewater, it is the most promising wastewater treatment method [2]. Ammonia nitrogen pollution in coke wastewater is becoming a major problem [3]. It is caused by cooled coal waste gas and ammonia produced by high temperature after dry distillation, or is caused in the process of wastewater treatment during which microbes react with inorganic nitrogen or organic nitrogen by means of biochemical reaction and chemical reaction. In this paper, we isolated and identified an efficient degradation of ammonia nitrogen capacity strains from industrial wastewater and conducted preliminary physiological and biochemical identification and provide alternative bacteria for the development of many types of highly efficient microbial agents.

\section{Materials and Methods}

\subsection{Materials}

1) The source of sample
Sediments of Miyun Longtan sewage treatment plant (saved in the refrigerator at $4^{\circ} \mathrm{C}$ ).

2) The main culture medium

a) The enriched medium: deionized water $500 \mathrm{~mL}$, $\mathrm{C}_{6} \mathrm{H}_{12} \mathrm{O}_{6} 2.5 \mathrm{~g},\left(\mathrm{NH}_{4}\right)_{2} \mathrm{SO}_{4} 1.0$ g, $\mathrm{K}_{2} \mathrm{HPO}_{4}-3 \mathrm{H}_{2} \mathrm{O} 0.5 \mathrm{~g}$, $\mathrm{NaCl} 1.0$ g, $\mathrm{MgSO}_{4} \cdot 7 \mathrm{H}_{2} \mathrm{O} 0.25 \mathrm{~g}, \mathrm{FeSO}_{4} \cdot 7 \mathrm{H}_{2} \mathrm{O} 0.2 \mathrm{~g}, \mathrm{pH}$ $7.2-7.4,121^{\circ} \mathrm{C}$ stream sterilization 20 mins.

b) The isolation medium: add $20 \%$ agar to the enriched medium, $121^{\circ} \mathrm{C}$ stream sterilization 20 mins.

c) The screening culture medium: $\left(\mathrm{NH}_{4}\right)_{2} \mathrm{SO}_{4}$ was added gradually, other components with the same as the isolation medium.

d) The activation medium: deionized water $500 \mathrm{~mL}$, beef extract $1.5 \mathrm{~g}$, peptone $5 \mathrm{~g}, \mathrm{NaCl} 2.5 \mathrm{~g}, \mathrm{pH} 7.2$ - 7.4, $121^{\circ} \mathrm{C}$ stream sterilization 20 mins.

\subsection{Methods}

1) Culture conditions

The sampling water was added at a ratio of $10 \%$ to enrichment culture medium containing $100 \mathrm{~m} / \mathrm{L}$ phenol and cultured at $30^{\circ} \mathrm{C}$ on a rotary shaker at $150 \mathrm{rpm} \cdot 1 \mathrm{~mL} 5 \%$ $\left(\mathrm{NH}_{4}\right)_{2} \mathrm{SO}_{4}$ solution was added in the enrichment culture medium to acclimation training same time each day, and continuing about 7 days. The enriched microorganisms were inoculated into new culture medium with a $5 \%$ inoculation quantity, and then repeat the above operation, continuing 7 days. The bacteria were cultured for two weeks with $\mathrm{NH}_{4}^{+}$as the only nitrogen resource. To obtain pure cultures, the strains were separated with a dilution-plate method.

2) Identification 
a) Morphology [4,5]

Some morphological characteristics of colonies was identified by the naked eye, such as shape, size, surface, edge, uplifted shape, transparency, wetness, roughness, colonies and medium color change, et al.

b) Physio-biochemical characteristics [6]

The physiological and biochemical reactions of sampled bacteria were tested, including Starch hydrolysis, (M.R) M.R test, Glucose fermentation, Sucrose fermentation, Indol test, (V.P) V.P test, Gelatin test, Citrate test, et al.

c) Molecular identification

The strain of the genome sequence is analyzed by 16SrDNA identification methods. Gene sequences were compared with those in the GenBank database using batch BLAST.

3) Ammonia nitrogen degradation experiment [7]

The startup of the experiments was obtained by inoculating $50 \mathrm{~mL}$ mineral cultures with $5 \mathrm{~mL}$ bacterial suspension which OD is about 1.50 , this cell suspension is available by inoculating bacteria for 1 day in liquid medium and then washed by distilled water. The influence factors of ammonia nitrogen concentration, inoculum volume, $\mathrm{pH}$ value, temperature, shaking revolution and adding carbon on phenol degradation were investigated. The ammonia nitrogen concentration increased from 50 to $600 \mathrm{mg} / \mathrm{L}$, the inoculum volumes were $3 \%, 5 \%, 10 \%$, $20 \%$, the initial $\mathrm{pH}$ values were $5,6,7,8,9$ and 10 , the temperature were $15^{\circ} \mathrm{C}, 20^{\circ} \mathrm{C}, 25^{\circ} \mathrm{C}, 30^{\circ} \mathrm{C}, 40^{\circ} \mathrm{C}$ and $45^{\circ} \mathrm{C}$, the shaking revolution are 50,100, 150, 200, 250 $\mathrm{r} / \mathrm{min}$, the adding carbon are $0,0.5,1,1.5,2.0$ and 2.5 $\mathrm{g} / \mathrm{L}$ glucose. During the period of batch culture, all samples were periodically taken for the concentration of ammonia nitrogen. All experiments were carried out in duplicate.

4) Analytical methods

In this article, the method of Nessler's reagent photometry was used to monitor the detection of ammonia nitrogen determination, and turbidimetry was used to determine the growth of the bacteria.

\section{Results and Analysis}

\subsection{Identification of Fungi}

1) Colony observation (Table 1)

2) Identification with PCR amplification

The strain was sampled from the wastewater treatment system of the Sediments of Miyun Longtan in Beijing and isolated under the laboratory condition. It was identified based on Gram staining, biochemical tests, and 16S rRNA sequence determination. The results showed that the strain $\mathrm{C}_{2}$ was identified as Bacillus amyloliquefaciens. Figure 1 showed the phylogenetic tree of the degrading bacteria $\mathrm{C}_{2}$.
Table 1. Physio-biochemical characteristics of the degrading bacteria physio-biochemical characteristics $C_{2}$.

\begin{tabular}{cc}
\hline The characteristic of physiology and biochemistry & $\mathrm{C}_{2}$ \\
\hline Starch hydrolysis & - \\
(M.R) M.R test & - \\
Glucose fermentation & + \\
Sucrose fermentation & + \\
Indol test & - \\
(V.P) V.P test & - \\
Gelatin test & + \\
Citrate test & - \\
\hline
\end{tabular}

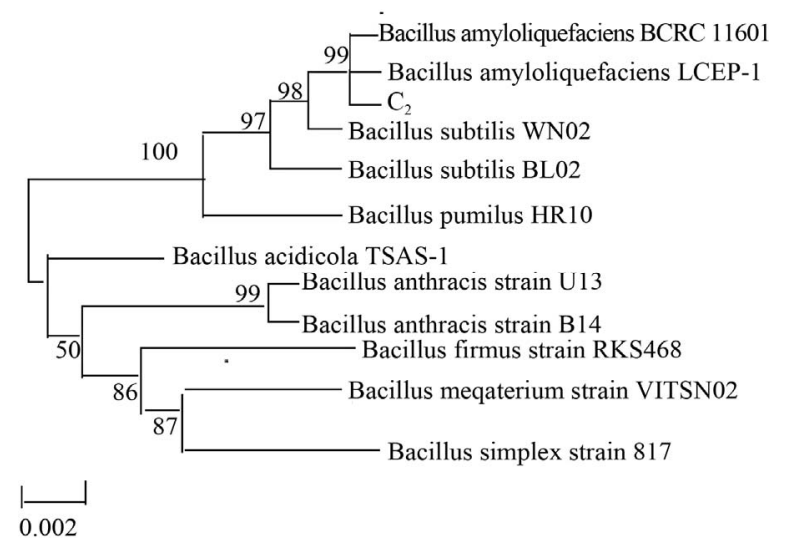

Figure 1. Phylogenetic tree of the degrading bacteria.

\subsection{Ammonia Nitrogen Degradation}

1) The effect of temperature

The temperature is an important factor of microbial survival, it influences the growth of microorganism and the absorption and utilization of growth substances [7] mainly through changing the activity of the enzyme. Figure 2 showed the effect of temperature on the ammonia nitrogen degradation using $\mathrm{C}_{2}$. The temperature ranges from $15^{\circ} \mathrm{C}$ to $45^{\circ} \mathrm{C}$. It can be seen that the optimal values of temperature was observed as $35^{\circ} \mathrm{C}$, and decreased gradually thereafter.

2) The effect of $\mathrm{pH}$ values

The initial $\mathrm{pH}$ values of the culture media affect microbial development. Having $\mathrm{pH}$ values that are either too high or too low are not conducive to cell growth $[8,9]$. Figure 3 showed the ammonia nitrogen degradation at the different $\mathrm{pH}$ values, ranging from 5 to 10 . When the $\mathrm{pH}$ value ranged from 5 to 7 , the degradation rate kept increasing. The degradation rate reached a maximum of $90 \%$ at $\mathrm{pH} 7$. After that, the degradation rate then decreased. This indicated that partial alkaline environment was conducive to the degradation of ammonia nitrogen by $\mathrm{C}_{2}$.

3) The effect of ammonia nitrogen concentration Figure 4 showed ammonia nitrogen degradation at the ammonia nitrogen of 50 - $600 \mathrm{mg} / \mathrm{L}$ with $10 \%$ starting inoculums. 50, 100, and $200 \mathrm{mg} / \mathrm{L}$ ammonia nitrogen could 


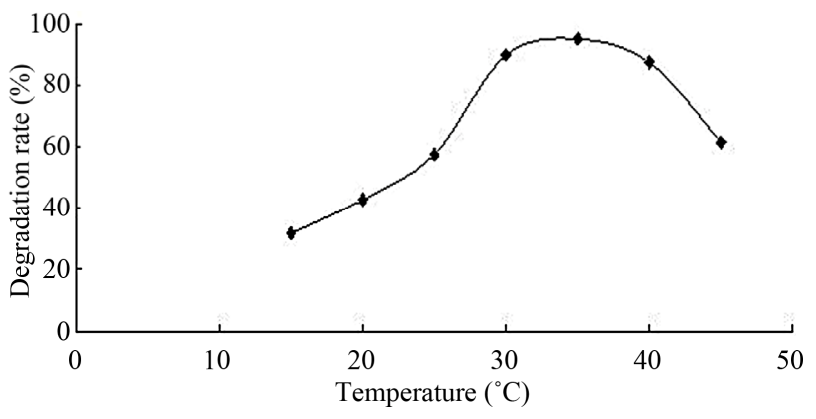

Figure 2. The effects of temperature on ammonia nitrogen degradation by $\mathrm{C}_{2}$.

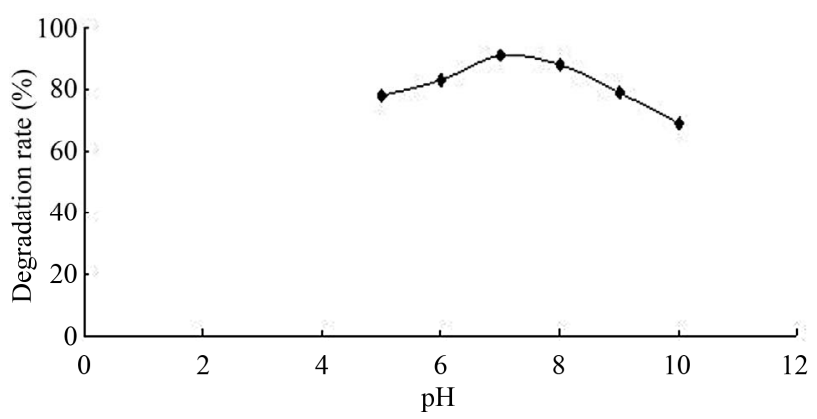

Figure 3. The effects of $\mathbf{p H}$ on ammonia nitrogen degradation by $\mathrm{C}_{2}$.

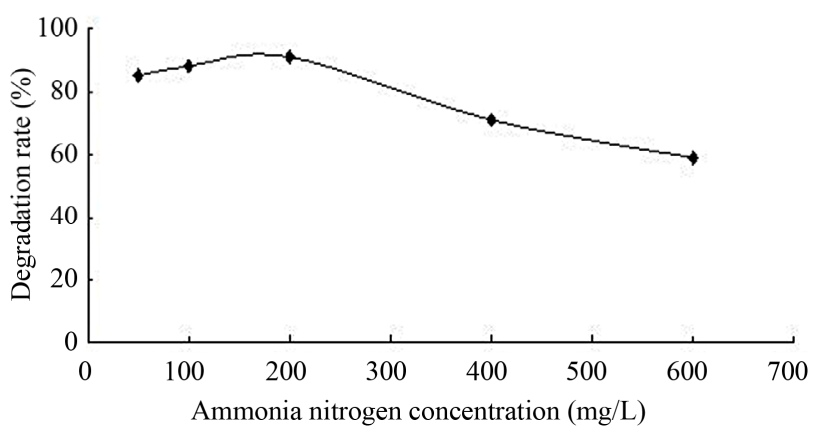

Figure 4. The ammonia nitrogen concentration degradation by $\mathrm{C}_{2}$ in the mineral medium containing initial ammonia nitrogen concentration from 50 to $600 \mathrm{mg} / \mathrm{L}$ with $10 \%$ starting inoculums.

be degraded above $80 \%$ by $\mathrm{C}_{2}$ within 48 h respectively. While the ammonia nitrogen degradation rates of the sample of 400, and $600 \mathrm{mg} / \mathrm{L}$, were decreased. It exhibited a remarkable augment of substrate inhibition, which could be also demonstrated by the longer lag phase of cell growth. The production and accumulation of various intermediates may be responsible for the decreased cell mass yield [10].

4) The effect of inoculums volume

Figure 5 indicated the effect of inoculums volume on ammonia nitrogen degradation after $24 \mathrm{~h}$. The cells inoculated with $10 \%$ starting inoculums manifested the high ammonia nitrogen-degrading velocity. The reasons were accounted as following: the increase of the quantity shortens the lag phase of the bacteria, which can quicken degradation of ammonia nitrogen.

5) The effect of carbon addition

The microbe with carbon source acts as growth nutrients, so different carbon sources have a different but great effect on the efficiency for the degradation of strains [11-13]. Figure 6 showed the effect of adding carbon concentration on the ammonia nitrogen degradation. The $\mathrm{C}_{2}$ degradation rate decreased when the sucrose concentration increased, because the overloaded glucose inhibited the ammonia nitrogen degradation. This indicated that ammonia nitrogen consumed in medium was utilized to synthesize new cells.

6) The effect of shaking revolution

Shaking revolution is a reflection of the bacterial ability to get oxygen in the process of the growth, bacteria will get more oxygen with a high speed, and get lower oxygen with a low speed [14,15]. Figure 7 indicated the effect of shaking revolution on ammonia nitrogen degradation after $48 \mathrm{~h}$. It can be seen that the optimal values of speed were observed as $200 \mathrm{r} / \mathrm{min}$, and decreased gradually thereafter.

\section{Conclusions}

\subsection{An Efficient Ammonia Nitrogen Degradation Strain Was Isolated}

Through the wastewater sludge concentration in training,

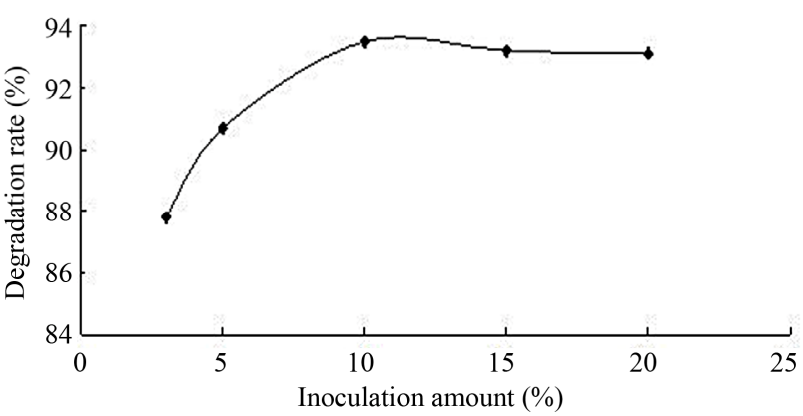

Figure 5. The effect of inoculums volume on ammonia nitrogen degradation.

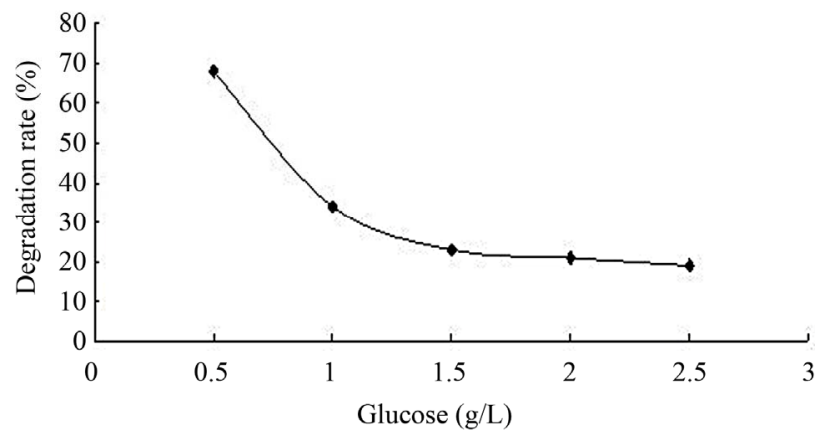

Figure 6. The effects of sucrose addition on ammonia nitrogen degradation by $\mathrm{C}_{2}$. 


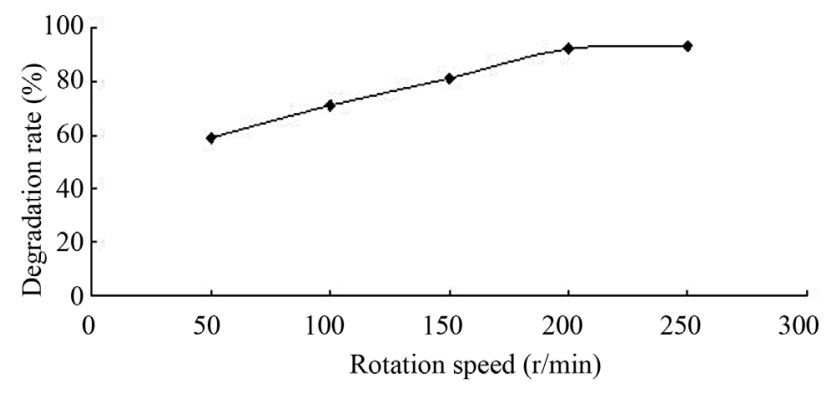

Figure 7. The effect of shaking revolution on ammonia nitrogen degradation by $\mathrm{C}_{2}$.

an efficient ammonia nitrogen degradation strain $\mathrm{C}_{2}$ was isolated, and was identified as Bacillus amyloliquefaciens.

\subsection{Efficient Degradation Characteristics of Strains on Degrading the Ammonia Nitrogen Wastewater}

Through the simulation of ammonia nitrogen wastewater, we set up different environment conditions, include the time, inoculums volume, temperature, $\mathrm{pH}$ value, ammonia nitrogen concentration, carbon addition and shaking revolution. The results showed that the $\mathrm{C}_{2}$ strains have an excellent degradation ability in the ammonia initial concentration of $200 \mathrm{mg} / \mathrm{L}$, $\mathrm{pH} 7.5$, temperature $35^{\circ} \mathrm{C}, 10 \%$ inoculum, shaking revolution $200 \mathrm{r} / \mathrm{min}$, and the degradation rate was $93 \%$ after cultured for $48 \mathrm{~h}$.

\section{REFERENCES}

[1] L. J. Yi and Z. H. Ma, "Improved Approach for Determination of Kjeldahl Nitrogen,” Shandong Water Resources Institute of the Eighth Outstanding Academic Assembly, 2003. (in Chinese)

[2] X. W. Gu, L. J. Gong, Q. L. Liu and C. Fen, "The Production, Hazards and Control of Ammonia Nitrogen in Pond Culture,” Fisheries to Get Rich Guide, 2011. (in Chinese)

[3] Z. L. Yang, J. L. Wan and H. Quan, "The Feasibility Study of Move Ammonia Nitrogen from Sewage," Nitrogen Fertilizer Technology, Vol. 32, No. 3, 2011, pp. 49-

\section{2. (in Chinese)}

[4] X. Z. Dong and M. Y. Cai, "Common Bacteria System Identification Manual,” Science Publishing House, Beijing, 2001, pp. 409-412. (in Chinese)

[5] R. E. Buchanan, "Bergey’s Manual of Determinative Bacteriology,” Science Publishing House, Beijing, 1984. (in Chinese)

[6] B. Zhao and S. J. He, "Microbiology Test," Science Publishing House, Beijing, 2002. (in Chinese)

[7] D. D. Focht and W. Verstraete, "Biochemical Ecology of Nitrification and Dinitrification," Advances in Microbial Ecology, Vol. 1, 1977, pp. 135-214.

[8] W. G. Ztimft, "The Biological Role of Nitrie Oxide in Bacteria," Archives of Microbiology, Vol. 160, No. 4, 1993, pp. 253-264. doi:10.1007/BF00292074

[9] B. K. Mobarry, M. Wagner, V. Urbain, et al., "Phylogenetic Probes for Analyzing Abundance and Spatial Organization of Nitrifying Bacteria," Applied and Environmental Microbiology, 1996, Vol. 62, No. 6, pp. 2156-2162.

[10] O. J. Hao, M. H. Kim, E. A. Seagren and H. Kim, "Kinetics of Phenol and Chlorophenol Utilization by Acinetobacter Species," Chemosphere, Vol. 46, No. 6, 2002, pp. 797-807. doi:10.1016/S0045-6535(01)00182-5

[11] Z. Zhu, "High Concentrations of Ammonia Nitrogen Wastewater Treatment Technology and Development," Environmental Science Survey, Vol. 27, No. 1, 2008, pp. 6061. (in Chinese)

[12] T. Y. Gao, "Water Pollution Control Engineering," Higher Education Press, Beijing, 2007. (in Chinese)

[13] X. T. Liu, et al., "Acidification-Biological Contact Oxidation Process in the Production of Vitamin C Wastewater,” Shanghai Environmental Science, Vol. 9, No. 6, 1990, pp. 11-15. (in Chinese)

[14] X. Y. Chen, et al., "Refractory Organic Matter Hydrolysis -Acidification Pretreatment," Environmental Protection of Chemical Industry, Vol. 16, No. 3, 1996, pp. 152-155. (in Chinese)

[15] S. F. Qiao, “The Accumulation Hazards and Biological Utilization of Ammonia Nitrogen in Farming Water," Hebei Fisheries, No. 2, 2006, pp. 20-22. (in Chinese) 